\title{
Karagöl (Borçka-Artvin) Gölü ve Çevresinin Hidrojeokimyasal İncelemesi
}

\author{
Hydrogeochemical Investigation of Karagöl (Borçka-Artvin) Lake and Its Vicinity \\ Şehnaz ŞENER $\mathbb{D}$, Hülya KİBAR $\mathbb{D}$ \\ Süleyman Demirel Üniversitesi, Mühendislik Fakültesi, Jeoloji Mühendisliği Bölümü, ISPARTA
}

Geliş (Received): 11 Mayıs (May) 2017, Düzeltme (Revised): 27 Temmuz (July) 2017, Kabul (Accepted): 03 Ağustos (August) 2017

\section{ÖZ}

Bu çalışmada, Karagöl ve çevresinin jeolojik ve hidrojeolojik özellikleri incelenerek bölgedeki su kaynaklarının hidrojeokimyasal özellikleri, kullanım durumları ve kirlilik değerlendirmeleri yapılmıştır. Çalışma alanında Üst Kretase-Kuvaterner zaman aralığında farklı yaş ve litolojiye sahip kaya birimleri yüzeylemektedir. Çalışma alanında yeraltısuyu rezervuarları alüvyon ve içerisinde yer yer kireçtaşı, kumtaşı seviyeleri olan kırık ve çatlaklı mağmatik kaya birimleri olup en önemli yüzey suları ise Çoruh Nehri ve Karagöl'dür. Çalışma alanındaki su kaynaklarının hidrojeokimyasal özelliklerini belirlemek amacıyla, yüzey suyu ve kaynak suyu örneklerinin hidrojeokimyasal analizleri yapılmıştır. Elde edilen sonuçlara göre bölgedeki su kaynaklarının, $\mathrm{Ca}-\mathrm{HCO}_{3}, \mathrm{Ca}-\mathrm{Mg}-\mathrm{HCO}_{3}$ ve $\mathrm{NaHCO}_{3}$ sular fasiyesinde olduğu görülmektedir. Su tiplerinin gelişmesindeki ana etken kayaç-su etkileşimi olup genel olarak $\mathrm{Na}$ ve $\mathrm{Ca}$ iyonlarının artışı $\mathrm{Na}$-Ca feldspatlar ile, $\mathrm{Mg}$ iyon artışı ise daha çok biyotit, amfibol, piroksen gibi silikat minerallerinin ayrışması sonucunda gerçekleşmektedir. Su örneklerindeki baskın $\mathrm{HCO}_{3}$ iyonu; kireçtaşı, killi kireçtaşı birimleri ile birlikte feldspat minerallerinin ayrışması sonucunda açığa çıkan kalsit mineralleri ile ilişkili kaya-su etkileşimi sonucunda artış göstermektedir. Su kalitesi bakımından incelendiğinde çalışma alanındaki suların tamamı I. su kalite sınıfında yer almakta olup yapılan değerlendirmelere göre içme ve sulama suyu olarak kullanıma uygundur.

Anahtar Kelimeler: Ayrışma, Hidrojeokimya, Hidrojeoloji, Karagöl.

\begin{abstract}
In this study, geological and hydrogeological properties of Karagöl and its surroundings were investigated and hydrogeochemical properties and quality of waters were evaluated. The rock units are observed with different age and lithology in the Upper Cretaceous-Quaternary time interval in the study area. The groundwater reservoirs are alluvium and fractured-fissured magmatic rock units with locally limestone, sandstone levels. The most important surface waters are Çoruh River and Karagöl Lake in the region. In order to determine hydrogeochemical properties of the surface and spring waters, hydrochemical analyses were performed. According to the obtained results, the water resources are in $\mathrm{Ca}-\mathrm{HCO}_{3}, \mathrm{Ca}-\mathrm{Mg}-\mathrm{HCO}_{3}$, and $\mathrm{NaHCO}_{3}$ facieses. The main factor in the development of water types is water-rock interactions. In general, increase of $\mathrm{Na}$ and $\mathrm{Ca}$ ions is related to $\mathrm{Na}$-Ca feldspars alteration, while the Mg ions are mainly due to the weathering of silicate minerals such as biotite, amphibole, pyroxene. On the other hand, dominant $\mathrm{HCO}_{3}$ ion shows an increase associated with limestone and clayey limestone units, and also with the secondary calcite minerals which are formed as a result of the feldspar mineral alteration. Water resources are classified as $1^{\text {st }}$ water quality in terms of all parameters and suitable for drinking and irrigation.
\end{abstract}

Keywords: Weathering, Hydrogeochemistry, Hydrogeology, Karagöl. 


\section{GİRIŞ}

İnsanoğlunun yarattı̆̆1 olumsuz koşullar nedeniyle kullanılabilirliğini yitiren yüzey sularının en önemli alternatifi yeraltısularıdır. Günümüzde yüzey sularının kullanıma kazandırılması kolay olmasına rağmen bu sular, bölgesel kirleticilerden çok daha kolay etkilenmektedir. $\mathrm{Bu}$ nedenle su ihtiyacinın karşılanmasında yeraltısuları daha önemli hale gelmiştir. Ancak, yeraltısularının sürdürülebilir kullanımı, plansız yönetimlere bağlı olarak aşırı çekimler ve kirleticiler sebebiyle tehlike altına girmektedir. Su kaynaklarının en etkin ve doğru şekilde kullanımı doğru su yönetimlerinin planlanmasına bağlıdır. $\mathrm{Bu}$ da kapsamlı hidrojeolojik ve hidrojeokimyasal incelemelerin yapılması ile mümkündür.

Artvin ili Borçka ilçesi sınırları içinde yer alan Karagöl, 368 hektar alana sahip olup, 14.08.2002 tarihinde Bakanlar Kurulu'nca tabiat parkı olarak ilan edilmiştir. Savgule ve Heba Dereleri sularını Karagöl'e taşıyarak gölün beslenmesini sağlamaktadır. Gölde biriken sular, bir drenajla kuzeydeki küçük göle oradan da bir başka drenajla Cosidenara Deresi'ne bağlanarak inceleme alanını terk etmekte ve nihayetinde Çoruh Nehri'ne ulaşmaktadır. Çoruh Nehri ve Karagöl çalışma alanındaki en önemli yüzey sularıdır. Ayrıca bölgede çok sayıda kaynak çıkış1 gözlenmektedir. Ancak, yüzey suyu ve yeraltısuyu potansiyeline sahip olan bölgedeki su kaynaklarının hidrojeokimyasal özellikleri daha önce incelenmemiş olup mevcut durumdaki kalitesi bilinmemektedir. Bu çalışmada Karagöl ve çevresinin jeolojik ve hidrojeolojik özellikleri değerlendirilerek çalışma alanındaki yüzey suyu ve kaynakların kimyasal özelliklerinin ortaya koyulması, kullanılabilirlik ve kalite durumunun belirlenmesi amaçlanmıştır.

\section{MATERYAL VE YÖNTEM}

\section{İnceleme Alanının Tanıtılması}

Çalışma alanı olarak seçilen Karagöl ve çevresi, Artvin ilinin Borçka ilçesi sınırları içinde yer almakta olup yaklaşı $410 \mathrm{~km}^{2}$ bir alanı kapsamaktadır (Şekil 1). Çalışma alanı Borçka merkez, Aralık köyü, İbrikli köyü, Kaynarca köyü, Balcı köyü, Erenler ve Tütüncüler ile çevrili olup F47A2, F47A3, F47B1, F47B2, F47B3 ve F47B4 paftaları içinde yer almaktadır. Karagöl ilçe merkezine $25 \mathrm{~km}$ uzaklıktadır. Borçka'nın 2007 Y1lı Genel Nüfus Sayımı verilerine göre toplam nüfusu 29.079'dur. İlçe merkezinin nüfusu 10.433, köy nüfusu ise 18.646 kişidir. Köy nüfusunun büyük bir kısmı çay, fındık, tütün ve orman ürünleriyle geçimini sağlamaktadır. 


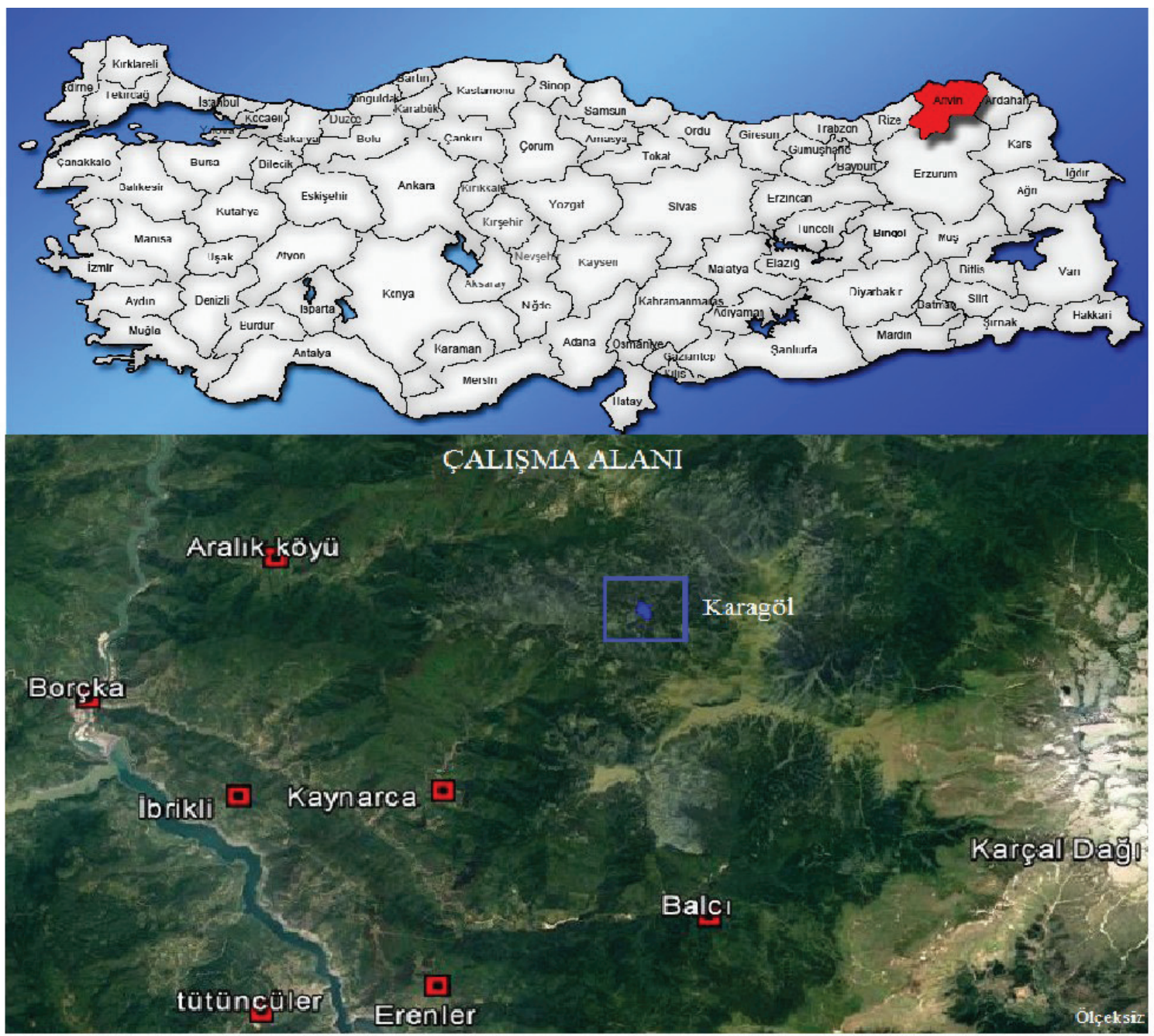

Şekil 1. Çalışma alanının yer bulduru haritası.

Figure 1. Location map of the study area.

\section{Yöntem}

Çalışma alanının, önceki çalışmalardan ve arazi çalışmalarından yararlanılarak 1/50.000 ölçekli jeoloji haritası hazırlanmıştır (Şekil 2). Litolojik birimlerin hidrojeolojik özellikleri dikkate alınarak bölgedeki geçirimli ve geçirimsiz birimler ayırtlanmıştır. Çalışma alanındaki yüzey ve kaynak sularının hidrojeokimyasal özelliklerini, kalitesini ve kullanım koşullarını belirlemek amaciyla Mayıs (2016) döneminde
17 adet su örneği alınmıştır. Örneklerin sıcaklık (T), elektriksel iletkenlik (EC) ve hidrojen iyonu aktivitesi $(\mathrm{pH})$ değerleri çok parametreli portatif su kalitesi ölçüm cihazları kullanılarak yerinde ölçülmüştür. Su örneklerinin katyon analizleri, Bureau Veritas Mineral (Kanada) laboratuvarı'1nda ICP-MS cihazı ile, anyon analizleri ise Süleyman Demirel Üniversitesi Jeotermal Enerji, Yeraltisuyu ve Mineral Kaynakları Araştırma ve Uygulama Merkezi 
laboratuvarında spektrofotometrik yöntem ve titrimetrik yöntemler kullanılarak yaptırılmıştır. Elde edilen analiz sonuçları kullanılarak, çalışma alanındaki suların iyon özellikleri, kullanım amaçları (içme ve sulama) ve kalite özellikleri incelenmiştir.

\section{JEOLOJI VE HIDROJEOLOJI}

Karagöl ve çevresi, jeotektonik bakımdan Doğu Karadeniz Dağları (Doğu Pontitler) içerisinde yer almaktadır. $\mathrm{Bu}$ kütleler Mesozoyik'te başlayıp Neojen sonlarına kadar süren Alp orojenezinin ve aynı dönemlere rastlayan volkanizmanın izlerini taşır (Kopar ve Sever, 2008). Saha genelinde, Mesozoyik ve Senozoyik yaşlı toleyitik ve kalko-alkalen kayaçlar izlenmektedir. Özellikle Üst Kretase dönemi bu bölümde yoğun şekilde volkanik aktivitenin görüldüğü dönem olup, asit ve bazik nitelikte periyodlarla kendini göstermiş, bu zamanın sonlarında ise volkanik aktivite denizaltı volkanizması şeklinde gelişme göstermiştir. Paleosen sonlarına doğru devam eden orojenik etkinlik Eosen'de de devam ederek denizel ortamda gerçekleşen yayılmaya bağlı olarak volkano-tortul istiflerin oluşmasına neden olmuştur (Güven ve Tosun, 1986; Y1lmaz vd., 1998).

Çalışma alanın 1/50000 ölçekli jeoloji haritası arazi ve literatür çalışmaları sonucunda hazırlanmış ve Şekil 2'de sunulmuştur. Çalışma alanı ve yakın çevresinin en yaşlı birimi Mesozoyik yaşlı Kızılkaya formasyonudur. $\mathrm{Bu}$ birimin üzerine sırasıyla Mesozoyik yaşlı Çağlayan formasyonu, Çayırbağı formasyonu ve
Mesozoyik-Senozoyikyaşl1Bakırköyformasyonu gelmektedir. Bakırköy formasyonunun üzerinde Senozoyik yaşlı Kabaköy formasyonu uyumsuz olarak yerleşmiştir. Tüm bu birimleri uyumsuz olarak örten Kuvaterner yaşl1 yamaç molozu ile alüvyon birimleri bulunmaktadır.

Kizılkaya formasyonu; gri, beyaz rekli riyodasitik-dasitik karakterli lav ve piroklastlarından oluşur. Lavlarda yer alan kolonlu yapılar ve yer yer de akıntılı (flüvdal) yapılar gözlenir. Hidrotermal girdiler sonucu sülfürlü mineralizasyon oluşumları ve buna bağ 1 olarak da yan kayaçlarda yer yer hidrotermal ayrışmalar (silişleşme, serizitleşme ve killeşme) mevcuttur. Formasyon içerisinde; piritleşme, silisleşme, kaolenleşme, serizitleşme, kloritleşme ve limonitleşme izlenen alterasyon ürünleridir. Kızılkaya formasyonu bazik volkano-tortul karakterli Çağlayan formasyonunu uyumlu olarak üzerler. Kızılkaya formasyonu içinde, fosil içerir tortul seviye bulunmadığından formasyonun yaşı göreceli olarak belirlenmiştir. Kızılkaya formasyonu çalışma alanı dışında gözlenen Turoniyen-Santoniyen yaşlı Çatak formasyonunu ve Kampaniyen-Mestristiyen yaşlı Çağlayan formasyonunu uyumlu olarak üzerlediğinden yaş1 göreceli olarak SantoniyenKampaniyen (Üst Kretase) olarak belirlenmiştir (Yılmaz vd., 1998). Çağlayan formasyonu; genellikle gri, yeşil renkli andezitik bazalt, bazalt lav ve piroklastları ile birlikte ardalanmalı olarak bulunan kırmızı-bordo renkli çamurtaşı, gri renkli marn ve kumtaşlarından oluşur. Formasyon içindeki tabakalarda bindirmenin etkisiyle gelişmiş dalgalı kıvrım yapıları görülür. Ayrıca, bazaltlarda yastık lav yapıları gelişmiştir. 


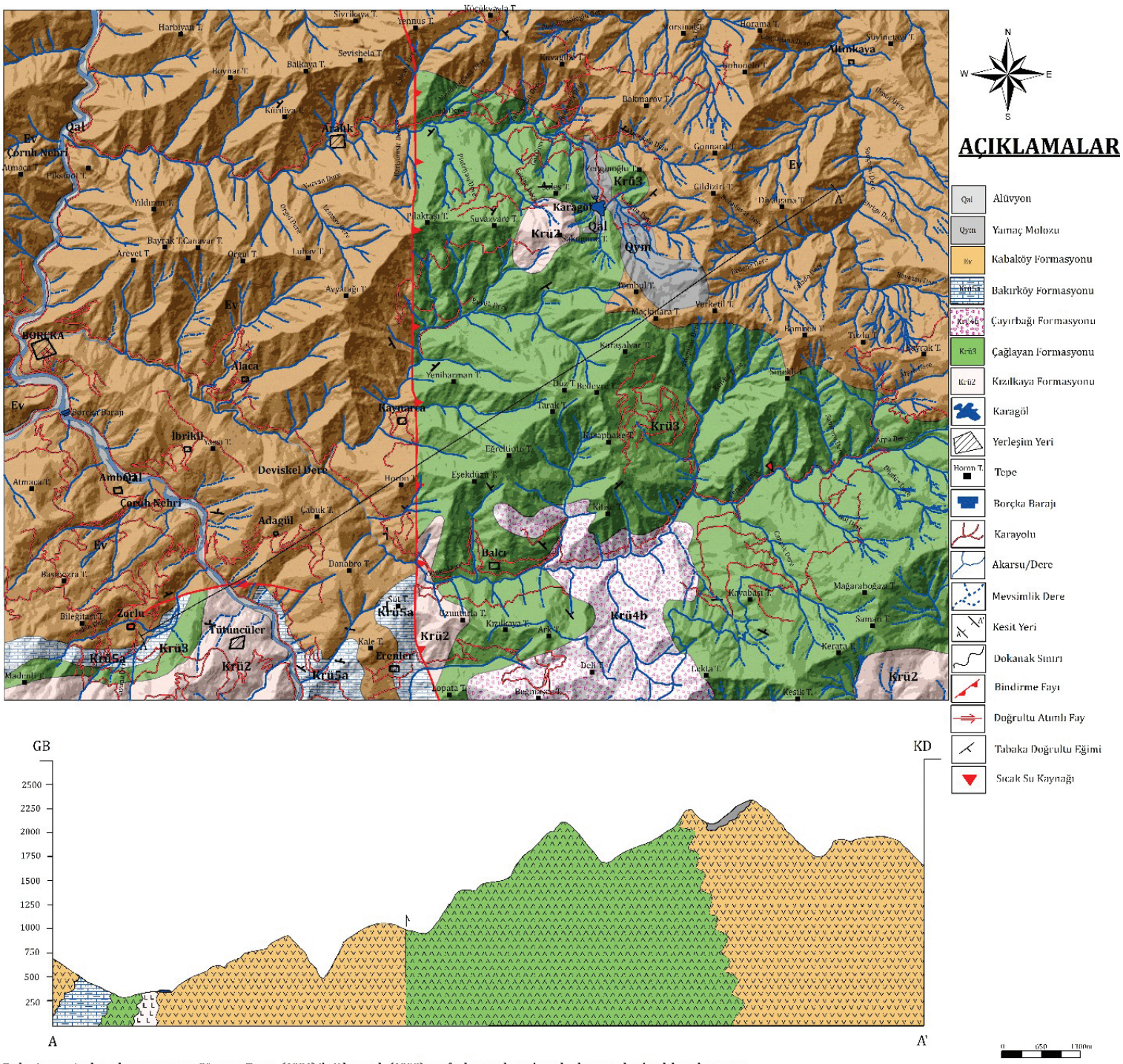

Bu harita arazi çalışmalarının yanısıra Güven ve Tosun, (1986) ile Yilmaz vd., (1998) tarafindan yapılan çalıșmalardan yararlamılarak hazırlanmıştr.

Şekil 2. Çalışma alanının jeoloji haritası ve enine kesiti.

Figure 2. Geological map and cross-section of the study area. 
Çağlayan formasyonu riyodasit-dasitik lav ve piroklastlarından oluşan Kızılkaya formasyonu üzerinde uyumlu olarak bulunur. Çağlayan formasyonunun yaşı, içerdiği fosil bileşenlerine göre Kampaniyen-Maestrihtiyen (Üst Kretase) olarak belirlenmiştir (Yılmaz vd., 1998). Birim, Borçka ilçesinin doğusunda, Karagöl'ün kuzeyinde, batısında ve güneyinde oldukça geniş bir alanda gözlenmektedir. Çayırbağ 1 formasyonu; fazla yaygın olmayan riyolit ve riyodasitik karakterli lav ve piroklastlarından meydana gelmiştir. Volkanojenik dom yapıları iyi gelişmiştir. Lavlarda prizmatik kolon yapıları ve akışkan yapılar görülmektedir. Çayırbağı formasyonunun üzerinde yanal geçişli ve uyumlu olarak Bakırköy formasyonu gelmektedir. Çayırbağ 1 formasyonunun içinde yaş verebilecek tortul seviyeler mevcut değildir. Ancak, Kampaniyen-Maestrihtiyen yaşlı Çağlayan formasyonunun üzerinde uyumlu olarak yer alması ve Maestrihtiyen-Paleosen yaşlı Bakırköy formasyonları ile de uyumlu olarak örtülmesi dolayısıyla formasyonun yaşı Maestrihtiyen olarak kabul edilmiştir (Yılmaz vd., 1998). Formasyon, çalışma alanında Balcı beldesinin kuzeydoğu ve güneydoğusunda dar alanlarda izlenmektedir. Bakırköy formasyonu; Borçka ilçesi Cankurtaran Geçidi yöresinde izlenen türbiditik karakterli bir birim olup genellikle killi kireçtaşı, marn, şeyl ve az oranda da kumtaşlarından oluşmuştur. Bakırköy formasyonu, Çayırbağı formasyonunun üzerinde yanal geçişli ve uyumlu olarak bulunmakta iken üstte Kabaköy formasyonu birim üzerine uyumsuz olarak gelmektedir. Bakırköy formasyonunun yaşı içerdiği fosil türlerine göre Maestrihtiyen-Paleosen olarak belirlenmiştir (Y1lmaz vd., 1998). Formasyon çalışma alanında Zorlu beldesinin güneyinde ve Erenler beldesinin kuzey ve batısinda izlenmektedir. Kabaköy formasyonu; kırmızı bir çimento matriksi ile tutturulmuş iri çakıllı konglomera seviyesi ile başlar. Çakıllar çoğunlukla bazalt, dasit ve granitten oluşur. Konglomera seviyesinin üzerine kumtaşı ve bol nummilitli kireçtaşları gelir. Toplam olarak 20-30 m kadar bir kalınlık gösteren bu taban seviyesi üzerinde kumtaş1, kumlu kireçtaşı ve marn ara tabakalı andezit lav ve piroklastları yer almaktadır. Kabaköy formasyonu bazik volkano-tortul bir seriden oluşan Çağlayan formasyonunun üzerine transgresif diskordan olarak gelmektedir. Üstte ise Kuvaterner birimler tarafindan uyumsuz olarak örtülmektedir. Çalışma alanında Borçka ilçesi, Muratlı ve Camili yörelerinde oldukça geniş bir alanda yüzeylenmektedir.

Kuvaterner birimlerden yamaç molozu; Karagöl'ün kuzey-güney doğrultusunda yer alan, tutturulmamış ve az tutturulmuş çamurtaş1, kumtaşı özellikte olan iri malzemelerden oluşmuştur. Birim genellikle üzerinde yer aldığ 1 birimin daha üst kotlarda mekanik olarak ayrışması ve su-rüzgar etkisiyle aşağı doğru taşınması sonucu oluşmuştur. Alüvyon ise yine Karagöl'ün çevresinde, akarsu yataklarında özellikle Çoruh Nehri'nin kenarlarında yüzeylenmektedir. Birim çakıl, kum, kil ve silt çökellerinden oluşmuştur. Bunlar, akarsuların getirdikleri güncel malzemelerdir. Birimin yaşı stratigrafik konumuna göre Kuvaterner'dir.

Çalışma alanında bulunan litolojik birimler, fiziksel ve hidrojeolojik özellikleri ile akifer olabilme potansiyelleri bakımından Az Verimli Gözenekli Akifer, Yersel Verimli Çatlaklı Kaya Akiferi ve Akifüj olmak üzere üç ayrı grupta incelenmiştir. Çalışma alanında yer alan Bakırköy formasyonu genel olarak şeyl, marn ve killi kireçtaşı içeriği nedeniyle "Akifüj” olarak; Kabaköy formasyonuna ait andezit, bazaltik lav, kireçtaş1, kumtaş1; Çayırbağ1 formasyonuna ait riyolitik, riyodasitik lav; Çağlayan formayonuna 
ait bazaltik lav, piroklast, çamurtaşı, kumtaş1 çökelleri; Kızılkaya formasyonuna ait dasit, riyodasit lav içerikleri ve kırık-çatlaklı yapıları nedeniyle "Yersel Verimli Çatlaklı Kaya Akiferi" olarak; alüvyon ve yamaç molozları ise bölgedeki yayılımları ve litolojik özellikleri dikkate alınarak "Az Verimli Gözenekli Akifer" olarak sınıflandırılmıştır.

Çalışma alanı içerisindeki en önemli yüzey suyu noktaları Çoruh Nehri ve Karagöl'dür. Elektrik üretmek amacı ile inşaa edilmiş Borçka Barajı, çalışma alanındaki önemli bir su yapısıdır. Ayrıca bölgede çok sayıda sürekli ve mevsimsel yüzeysel akış ile su kaynakları bulunmaktadır. Ancak, çalışma alanında yeraltısuyu derinliğini ve akifer karakteristiklerini belirlemede yardımcı olacak sondaj kuyusu ve/veya sığ kuyu bulunmamaktadır. $\mathrm{Bu}$ nedenle, çalışma kapsamında bölgenin yeraltısuyu seviye ve dinamiği ile birlikte akiferin permeabilite, transmisibilite, depolama katsayısı gibi karakteristik özellikleri hakkında bilgi elde edilememiştir.

\section{HIDROJEOKIMYA}

Hidrojeokimyasal değerlendirmede kullanılan su örneklerinin alındığ 1 lokasyonlar Şekil 3'te gösterilmiştir. Çalışma alanı içerisinde bulunan yüzey ve kaynak sularının iyon özelliklerinin belirlenmesi amacıyla; sertlik, hidrojen iyonu aktivitesi (pH), özgül elektriksel iletkenlik (EC), sodyum adsorbsiyon oran1 (SAR) ve sodyum iyon yüzdesi $(\% \mathrm{Na})$ gibi genel kimyasal özellikler değerlendirilmiştir. Aynı zamanda, suların sinıflandirılmasinda $\mathrm{su}$ örneklerinin major anyon ve katyon $\left(\mathrm{Ca}^{+2}\right.$, $\left.\mathrm{Mg}^{+2}, \mathrm{Na}^{+}, \mathrm{K}^{+}, \mathrm{SO}_{4}^{-2}, \mathrm{Cl}^{-}, \mathrm{HCO}_{3}^{-}, \mathrm{CO}_{3}^{-2}\right)$ analiz sonuçlarından yararlanılmıştır (Çizelge 1). Ayrıca su örneklerinin major iyonlara ait analiz sonuçları kullanılarak çalışma alanının hidrojeokimyasal özellikleri harita üzerinde gösterilmiştir (Şekil $3)$.

Suların sertliği kalsiyum, magnezyum, bikarbonat iyonları olmak üzere, $\mathrm{Ca}-\mathrm{Mg}$ sülfat, $\mathrm{Ca}-\mathrm{Mg}$ nitrat ve +2 veya daha yüksek

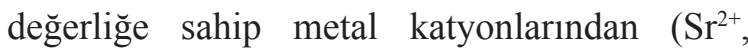
$\mathrm{Mn}^{2+}, \mathrm{Fe}^{2+}, \mathrm{Fe}^{+3}, \mathrm{Al}^{+3}$ ) ileri gelmektedir (Şahinci, 1991). Ülkemizde suların sertlik derecesini belirtmek için Fransız Sertlik Derecesi ( $\left.{ }^{\circ} \mathrm{F}\right)$ kullanılmaktadır. Çalışma alanındaki suların toplam sertlik değerleri $1.82^{\circ} \mathrm{F}$ ile $16.2^{\circ} \mathrm{F}$ arasında değişmekte olup KG-14 nolu su örneği 'az sert sular' sinıfında, KG-12, KG-13, KG-17 nolu su örnekleri 'yumuşak sular' sınıfında, diğer tüm su örnekleri ise 'çok yumuşak sular' sınıfında yer almaktadır. Çalışma alanındaki su örneklerin $\mathrm{pH}$ değerleri 7.28 - 9.21 arasında olup genel olarak "Bazik" ve "Bazik karakterli" sular sinıfinda yer almaktadır (Çizelge 1). Çalışma alanından alınan su örneklerinin özgül elektriksel iletkenlik değerleri yerinde ölçümler ile belirlenmiş olup 53-150 $\mu \mathrm{S} / \mathrm{cm}$ arasında değişmektedir. Çalışma alanındaki yüzey sularının analiz sonuçları kullanılarak hesaplanan Sodyum adsorbsiyon oranı (SAR) değerleri genel olarak 0.15 ile 0.37 arasında, \% Na değerleri ise 5.54-22.70 arasında değişmektedir.

\section{Suların Kimyasal Sinıflaması}

Çalışma alanındaki yüzey ve kaynak sularını temsil eden su örneklerine ait analiz sonuçları Piper Diyagramı üzerinde gösterilerek $\mathrm{su}$ örneklerinin hidrojeokimyasal fasiyesleri belirlenmiştir (Şekil 4). Buna göre, KG-1 nolu su örneği dışındaki tüm yüzey ve kaynak suyu örnekleri; alkali toprak elementlerin toplamı $(\mathrm{Ca}+\mathrm{Mg})$, alkali elementlerin toplamindan $(\mathrm{Na}+\mathrm{K})$ büyük, zayıf asit kökleri toplamının $\left(\mathrm{HCO}_{3}+\mathrm{CO}_{3}\right)$ güçlü asit köklerinin toplamından $\left(\mathrm{SO}_{4}+\mathrm{Cl}\right)$ büyük ve karbonat sertliği \% 50'den 
Şener, Kibar

fazla olan suları temsil etmektedir. Piper Diyagramı'na göre su örneklerinin tamamının genel olarak $\mathrm{Ca}-\mathrm{HCO}_{3}$ ve $\mathrm{Ca}-\mathrm{Mg}-\mathrm{HCO}_{3}$ 'lü sular fasiyesinde olduğu görülmektedir. KG-1 nolu su

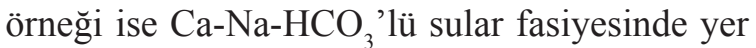
almaktadır.

$\mathrm{Bu}$ durum, su örneklerinin kayaç-su etkileşiminden kaynaklanmaktadır. Genel olarak çalışma alanında yersel verimli çatlaklı kaya akiferini temsil eden formasyonlar; andezit, dasit ve bazalt lavları ile piroklastik kayaçlar ve yer yer tabakalı kumtaşı, kireçtaşı, marn seviyelerini içermektedirler. Ortaç ve mafik magmatik kayaçlarda yoğun olarak $\mathrm{Na}-\mathrm{Ca}$ feldspat ve koyu renkli silikat mineralleri (biyotit, amfibol, piroksen) hakimdir. Genel olarak $\mathrm{Na}$ ve $\mathrm{Ca}$ iyonlarının artışı $\mathrm{Na}-\mathrm{Ca}$ feldspatlar ile, $\mathrm{Mg}$ iyonları ise daha çok biyotit, amfibol, piroksen gibi silikat minerallerinin ayrışması sonucunda gerçekleşmiş olabilir. Su örneklerindeki baskın $\mathrm{HCO}_{3}$ iyonu ise bölgede yer yer çökelmiş olan kireçtaşı, killi kireçtaşı birimleri ile birlikte feldispat minerallerinin ayrışması sonucunda açığa çıkan kalsit mineraleri ile ilişkili kayasu etkileşimi sonucunda artış göstermektedir. Ayrıca, bölgedeki magmatik kayaçların kırık ve çatlaklarında yoğun olarak kalsit dolguları bulunmakta olup, bu çatlaklar içerisindeki yeraltısuyu, kalsit mineralini kolaylıkla çözerek $\mathrm{HCO}_{3}$ iyonu bakımından zenginleşmektedir.

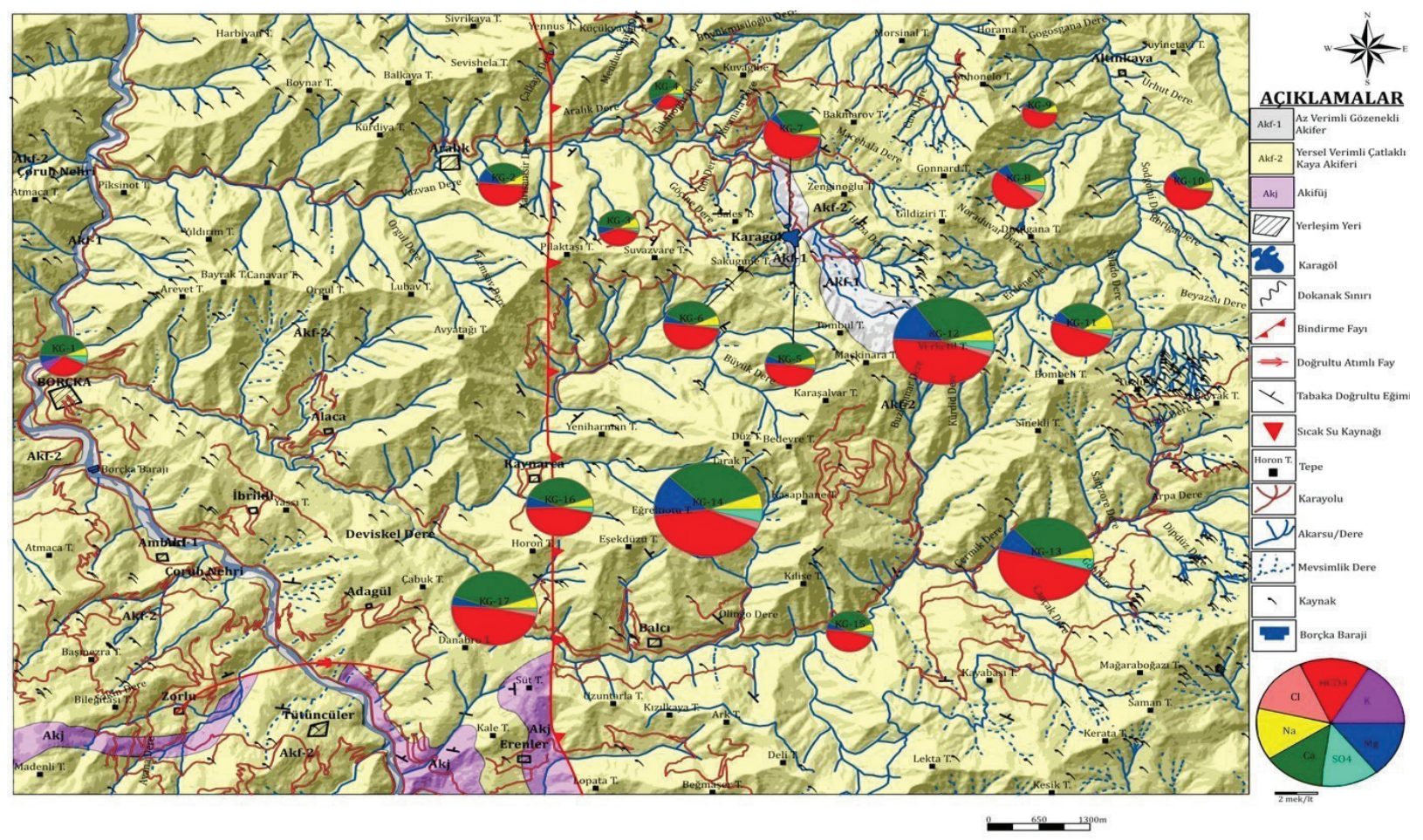

Şekil 3. Su ana iyon konsantrasyonları dağılımlarının harita üzerinde gösterimi.

Figure 3. Presentation of major ion concentration distributions on the map. 


\begin{tabular}{|c|c|c|c|c|c|c|c|c|c|c|c|c|c|c|c|c|c|}
\hline 的音 & 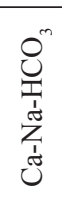 & 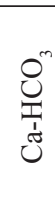 & 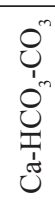 & $\begin{array}{l}0^{m} \\
\bigcup_{0}^{n} \\
0\end{array}$ & $\underbrace{0_{0}^{m}}_{\substack{1 \\
0}}$ & 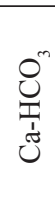 & 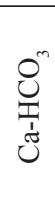 & $\overbrace{\substack{1 \\
d}}^{\infty}$ & $\overbrace{\substack{1 \\
\tilde{d}}}^{\infty}$ & 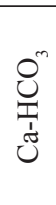 & 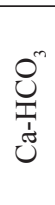 & 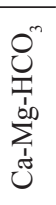 & $\underbrace{\int_{0}^{m}}_{\substack{1 \\
d}}$ & 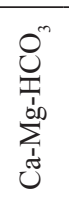 & $\overbrace{\substack{1 \\
0}}^{\infty}$ & 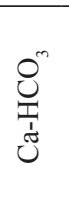 & 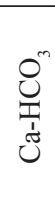 \\
\hline 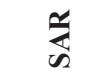 & $\frac{n}{0}$ & $\stackrel{\overbrace{}}{0}$ & ત્ & $\stackrel{7}{0}$ & $\stackrel{1}{0}$ & ત્ & $\stackrel{0}{\circ}$ & ત્ & $\stackrel{\infty}{\circ}$ & $\stackrel{5}{0}$ & $\hat{3}$ & त̂ & $\stackrel{\overbrace{}}{0}$ & @ి & $\stackrel{1}{0}$ & $\stackrel{\infty}{\stackrel{0}{0}}$ & $\tilde{\overbrace{}}$ \\
\hline$\frac{\pi}{0}$ & 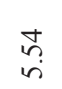 & $\stackrel{m}{I}$ & $=$ & $\begin{array}{l}\hat{6} \\
\dot{1}\end{array}$ & $\begin{array}{l}\infty \\
\stackrel{\bigcup}{J}\end{array}$ & 吉 & $\overrightarrow{\mathrm{I}}$ & $\begin{array}{l}0 \\
\stackrel{d}{\longrightarrow}\end{array}$ & $\stackrel{\circ}{\circ}$ & $\stackrel{n}{n}$ & $\hat{i}$ & $\begin{array}{l}\infty \\
\infty \\
\infty\end{array}$ & $\dot{a}$ & $\stackrel{\infty}{\stackrel{0}{0}}$ & $\underline{\sim}$ & 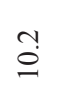 & $\stackrel{\circ}{\stackrel{0}{\circ}}$ \\
\hline $\bar{a}$ & $\underset{\infty}{0}$ & $\stackrel{\infty}{\stackrel{N}{r}}$ & $\underset{\infty}{ \pm}$ & $\hat{\sigma}_{\infty}$ & $\stackrel{\infty}{\infty}$ & $\underset{\infty}{\stackrel{Ð}{*}}$ & $\stackrel{\infty}{\sim}$ & $\stackrel{n}{\infty}$ & $\stackrel{\sigma}{r}$ & $\underset{\infty}{\infty}$ & $\underset{\infty}{\infty}$ & $\ddot{a}$ & $\underset{\infty}{\vec{\infty}}$ & $\underset{\infty}{\stackrel{\infty}{\infty}}$ & $\begin{array}{l}\vec{n} \\
\infty\end{array}$ & $\underset{\infty}{\vec{\infty}}$ & $\vec{\sim}$ \\
\hline 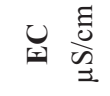 & J & 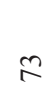 & I & $\tilde{6}$ & $\infty$ & 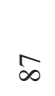 & ஸె & 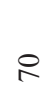 & $\tilde{n}$ & 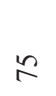 & $\infty$ & 呈 & $\stackrel{\infty}{\stackrel{\infty}{n}}$ & : & $\stackrel{2}{2}$ & $\hat{\sigma}$ & $\widehat{\cong}$ \\
\hline 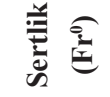 & $\stackrel{\infty}{i}$ & $\stackrel{\infty}{\stackrel{\infty}{i}}$ & $\overrightarrow{\vec{i}}$ & $\stackrel{\sim}{\sim}$ & $\stackrel{+}{i}$ & $\stackrel{\alpha}{\grave{i}}$ & $\stackrel{\text { I }}{i}$ & $\stackrel{m}{i}$ & $\underset{\text { Sం }}{\infty}$ & $\underset{i}{\Delta}$ & $\stackrel{8}{\stackrel{m}{m}}$ & \pm & $\begin{array}{l}\infty \\
\stackrel{\circ}{2}\end{array}$ & $\stackrel{\overbrace{}}{\sigma}$ & $\stackrel{\sim}{i}$ & $\begin{array}{l}\frac{n}{n} \\
i n\end{array}$ & $a$ \\
\hline Ð் & $\begin{array}{l}8 \\
\pm \\
\pm\end{array}$ & $\begin{array}{l}\stackrel{8}{g} \\
\stackrel{2}{2}\end{array}$ & $\begin{array}{l}\text { กิ } \\
\text { อ }\end{array}$ & $\begin{array}{l}\text { in } \\
\text { in }\end{array}$ & 8 & $\begin{array}{l}\infty \\
\stackrel{1}{1}\end{array}$ & 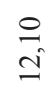 & $\begin{array}{l}\stackrel{\text { N }}{\stackrel{5}{=}} \\
\end{array}$ & $\begin{array}{l}\stackrel{9}{I} \\
\text { I }\end{array}$ & $\begin{array}{l}\infty \\
\stackrel{1}{-1}\end{array}$ & 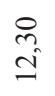 & $\stackrel{R}{\stackrel{0}{0}}$ & $\stackrel{0}{=}$ & $\begin{array}{l}2 \\
i\end{array}$ & $\begin{array}{l}\infty \\
\infty \\
\pm\end{array}$ & $\begin{array}{l}\infty \\
\stackrel{0}{0}\end{array}$ & $\begin{array}{l}8 \\
n \\
n\end{array}$ \\
\hline$e^{n} \frac{\bar{s}}{\square}$ & $\stackrel{t}{0}$ & 0 & ț & $\stackrel{\infty}{\circ}$ & $\stackrel{t}{\circ}$ & กֶ. & 0 & กै & กั & กี & กֶ & ชี & 0 & ơ & 0 & ơ & ชี \\
\hline 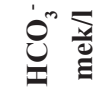 & $\stackrel{+}{\circ}$ & $\dot{0}$ & $\stackrel{t}{0}$ & กֶ. & $\hat{o}$ & $\hat{o}$ & $\exists$ & $\stackrel{\infty}{\circ}$ & $\stackrel{+}{\circ}$ & $\stackrel{\infty}{0}$ & $\exists$ & $\begin{array}{l}\stackrel{0}{i} \\
\vec{i}\end{array}$ & $\underset{\sim}{\stackrel{0}{i}}$ & $\begin{array}{l}\infty \\
i\end{array}$ & $\stackrel{\bullet}{\circ}$ & $\stackrel{\sim}{\sim}$ & $\stackrel{\circ}{i}$ \\
\hline $\mathrm{O}^{+} \mathrm{Q}^{+}$ & $\frac{0}{0}$ & $\stackrel{t}{\circ}$ & 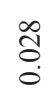 & ஸे & $\tilde{\overbrace{}}$ & ஜ̊. & ڤి. & ?̊. & : & ֻั & ڤ̊․ & ڤิ) & तี้ & $\stackrel{\vec{\infty}}{\stackrel{0}{0}}$ & ஸे. & $\begin{array}{l}0 \\
\vdots \\
0\end{array}$ & 苍 \\
\hline 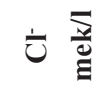 & $\stackrel{\overbrace{}}{0}$ & $\stackrel{\infty}{0}$ & $\stackrel{2}{0}$ & 훙 & $\frac{n}{0}$ & oे & $\stackrel{2}{0}$ & 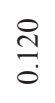 & $\stackrel{\infty}{\circ}$ & छे. & ڤ̂. & $\stackrel{N}{\overparen{0}}$ & \begin{tabular}{l}
\multirow{2}{*}{} \\
:
\end{tabular} & $\stackrel{5}{:}$ & $\stackrel{\infty}{\circ}$ & त् & $\begin{array}{l}\infty \\
\dot{0} \\
0\end{array}$ \\
\hline 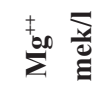 & $\stackrel{n}{o}$ & $\stackrel{2}{\circ}$ & 令 & $\begin{array}{l}0 \\
\stackrel{0}{0} \\
0\end{array}$ & $\begin{array}{l}\overline{0} \\
\dot{0}\end{array}$ & ồ & oे & $\stackrel{2}{3}$ & 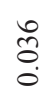 & : & $\stackrel{n}{n}$ & $\begin{array}{l}\tilde{n} \\
\infty \\
0 \\
0\end{array}$ & 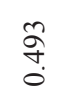 & ț̊ & م્م & $\stackrel{+}{\stackrel{0}{0}}$ & $\overrightarrow{5}$ \\
\hline 耗 & $\begin{array}{l}\text { ర్ } \\
n \\
0\end{array}$ & ڤू & ?े & $\begin{array}{l}\text { ले } \\
\text { ? }\end{array}$ & 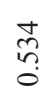 & $\underbrace{\infty}_{0}$ & $\begin{array}{l}\text { n } \\
n \\
0\end{array}$ & ঙे. & 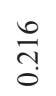 & $\begin{array}{l}\hat{\infty} \\
\tilde{m} \\
0\end{array}$ & $\begin{array}{l}0 \\
0 \\
0 \\
0\end{array}$ & $\stackrel{\stackrel{n}{ }}{=}$ & $\underset{-}{\stackrel{+}{\circ}}$ & 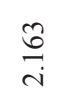 & \begin{tabular}{l}
$\overrightarrow{5}$ \\
\multirow{0}{0}{} \\
0
\end{tabular} & $\hat{\alpha}$ & : \\
\hline 声 & ồ & $\stackrel{\Delta}{0}$ & $\stackrel{0}{0}$ & $\hat{o}$ & ठ̊. & $\stackrel{8}{\circ}$ & @े & \&̊. & छั & $\hat{o}$ & $\stackrel{\infty}{\circ}$ & $\stackrel{\Delta}{0}$ & $\stackrel{0}{0}$ & $\stackrel{\Delta}{\circ}$ & $\stackrel{0}{\circ}$ & 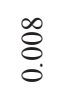 & $\stackrel{0}{0}$ \\
\hline 西 & $\begin{array}{l}\mathscr{0} \\
\stackrel{0}{0} \\
0\end{array}$ & $\stackrel{\infty}{=}$ & $\stackrel{\circ}{0}$ & $\stackrel{m}{0}$ & $\stackrel{o}{0}$ & $\stackrel{\pi}{\stackrel{1}{0}}$ & $\stackrel{8}{0}$ & $\frac{n}{0}$ & Oֶ. & $\stackrel{\infty}{\circ}$ & הి & त̂ & ते & $\underset{\substack{\infty \\
0 \\
0}}{0}$ & $\begin{array}{l}\overrightarrow{0} \\
\stackrel{0}{0} \\
0\end{array}$ & $\stackrel{+}{m}$ & तิ \\
\hline$\stackrel{\Xi}{\Xi}$ & $\overrightarrow{0}$ & 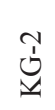 & $\stackrel{?}{b}$ & $\underset{\forall}{\forall}$ & 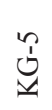 & 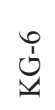 & $\hat{v}$ & $\begin{array}{l}\infty \\
0 \\
\qquad \\
y\end{array}$ & 仓ે & $\frac{0}{\dot{b}}$ & $\vec{J}$ & $\frac{1}{b}$ & $\frac{m}{\overrightarrow{0}}$ & $\frac{d}{b}$ & $\frac{n}{b}$ & $\frac{0}{1}$ & $\frac{\bar{b}}{\Delta}$ \\
\hline 竞 & 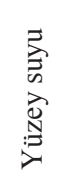 & 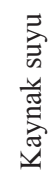 & 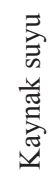 & 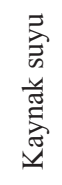 & 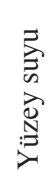 & 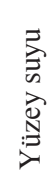 & 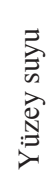 & 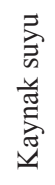 & 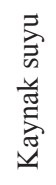 & 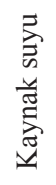 & 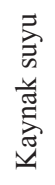 & 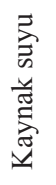 & 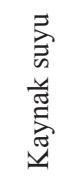 & 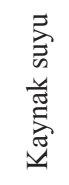 & 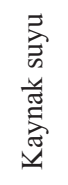 & 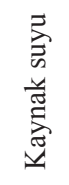 & 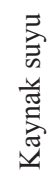 \\
\hline$\frac{\bar{y}}{\frac{\pi}{d}}$ & $\begin{array}{l}\vec{z} \\
\bar{z} \\
z \\
\bar{\Xi} \\
0 \\
0\end{array}$ & $\begin{array}{l}\vec{y} \\
\frac{\vec{y}}{4}\end{array}$ & $\frac{\pi}{\frac{\pi}{\pi}}$ & 害 & 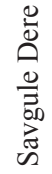 & 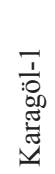 & 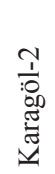 & 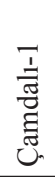 & 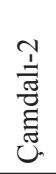 & 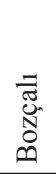 & 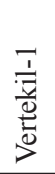 & $\begin{array}{l}\frac{N}{\vec{n}} \\
\frac{1}{0} \\
\frac{0}{0} \\
>\end{array}$ & 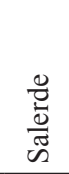 & $\frac{\overrightarrow{\tilde{U}}}{\mathscr{\varpi}}$ & 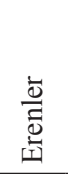 & 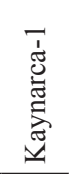 & 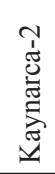 \\
\hline
\end{tabular}


Şener, Kibar

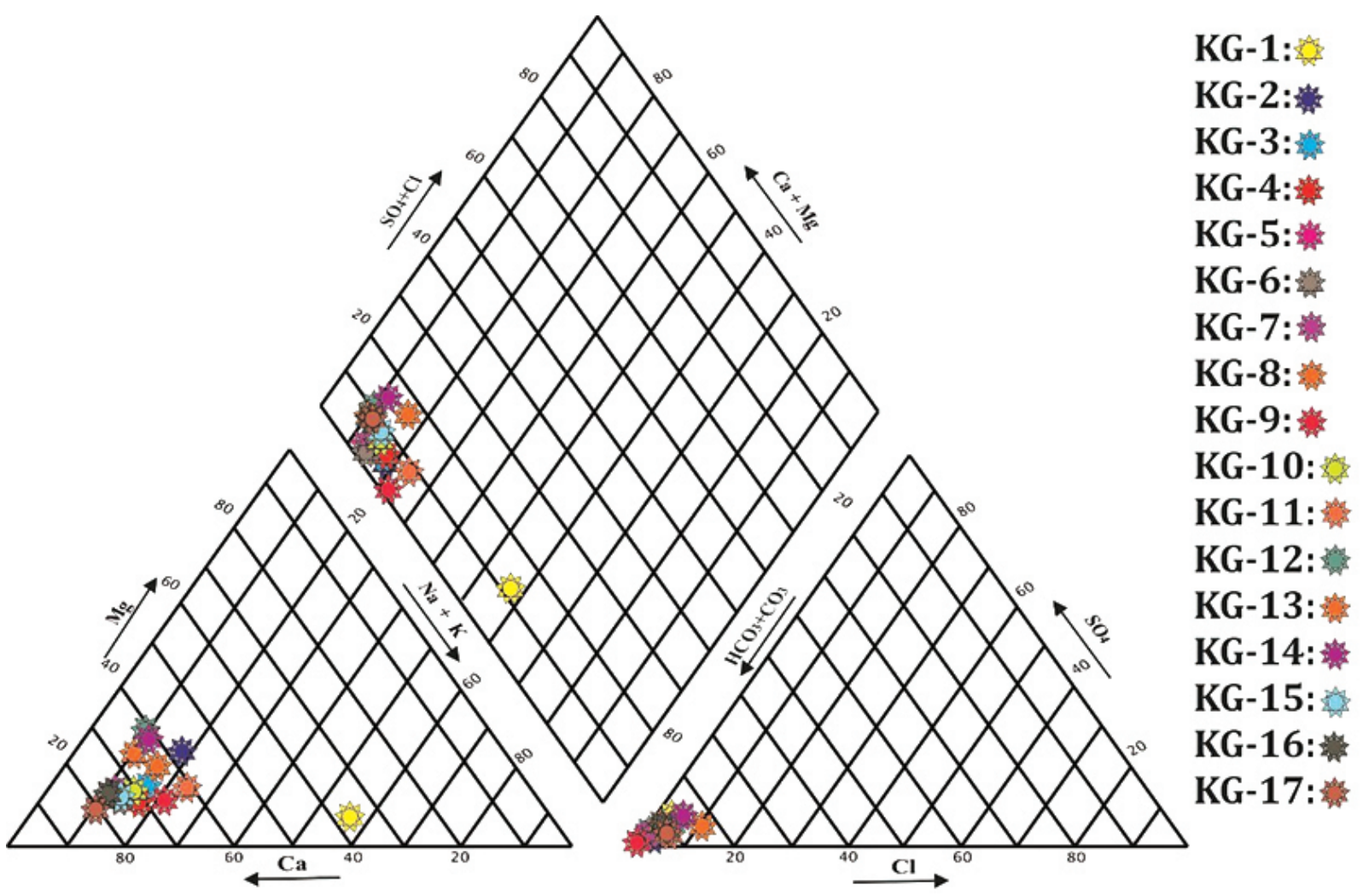

Şekil 4. Analiz edilen su örneklerin Piper Diyagramı.

Figure 4. Piper Diagram of the water samples analysed .

Çalışma alanında belirlenen su tipinin hangi işlev ve/veya mekanizma sonucu değiştiğini belirleyebilmek için, su örneklerinin iyonik oranları Gibss Diyagramı üzerine yerleştirilmiştir. Gibss Diyagramı'nda, su örneklerinin tamamı “Kayaç Baskın” bölgesine düşmektedir (Şekil 5). $\mathrm{Bu}$ da, su kimyasinı kontrol eden ana mekanizmanın, kayaç yapıcı minerallerin kimyasal ayrışması olduğunu göstermektedir.

\section{Major iyonların İstatistiksel değerlendirilmesi}

Çalışma alanındaki su örneklerinde ölçülen iyonların birbirleri ile ilişkilerini belirlemek için öncelikle korelasyon analizi yapılmıştır. Su örneklerinin analiz sonuçlarına göre $\mathrm{Ca}$ iyonu, $\mathrm{Na}$ ve $\mathrm{HCO}_{3}$ ile çok yüksek pozitif korelasyon, $\mathrm{Mg}, \mathrm{Cl}$ ve $\mathrm{SO}_{4}$ ile yüksek pozitif korelasyon sunmaktadır. $\mathrm{Mg}$ iyonu, $\mathrm{SO}_{4}$ ile çok yüksek pozitif korelasyona, $\mathrm{Na}$ iyonu ise $\mathrm{HCO}_{3}$ ile çok yüksek pozitif korelasyona sahiptir (Çizelge 2). $\mathrm{K}$ iyonu ise diğer tüm iyonlar ile negatif korelasyon göstermektedir. 


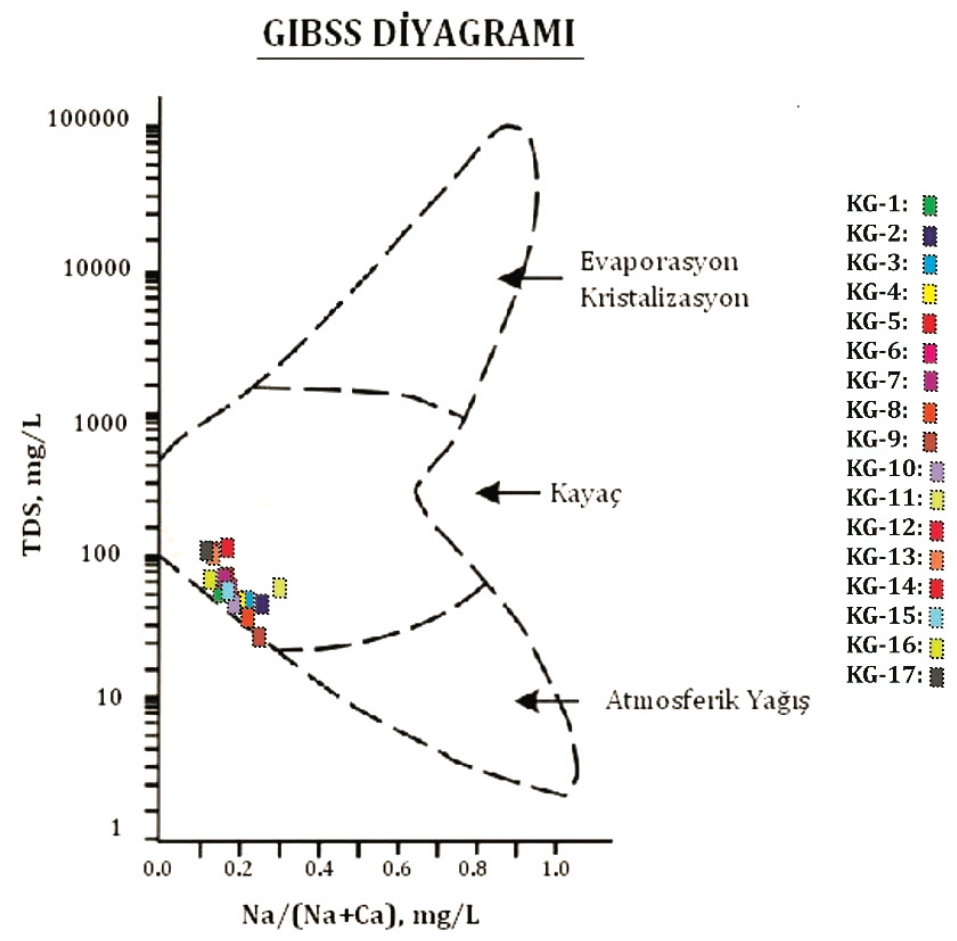

Şekil 5. Analiz edilen su örneklerin Gibss Diyagramı.

Figure 5. Gibss Diagram of the water samples analysed.

Çizelge 2. İnceleme alanındaki suların korelasyon katsayıları.

Table 2. Correlation coefficients of the waters in the study area.

\begin{tabular}{|c|c|c|c|c|c|c|c|c|c|}
\hline Parametreler & $\mathbf{p H}$ & EC & $\mathrm{Ca}^{+2}$ & $\mathbf{M g}^{+2}$ & $\mathrm{Na}^{+}$ & $\mathbf{K}^{+}$ & $\mathrm{Cl}^{-}$ & $\mathrm{HCO}_{3}^{-}$ & $\mathrm{SO}_{4}^{-2}$ \\
\hline pH & 1 & & & & & & & & \\
\hline EC & 0.633 & 1 & & & & & & & \\
\hline $\mathrm{Ca}^{+2}$ & 0.648 & 0.977 & 1 & & & & & & \\
\hline $\mathbf{M g}^{+2}$ & 0.467 & 0.840 & 0.867 & 1 & & & & & \\
\hline $\mathbf{N a}^{+}$ & 0.496 & 0.881 & 0.911 & 0.877 & 1 & & & & \\
\hline $\mathbf{K}^{+}$ & 0.172 & 0.013 & -0.096 & -0.112 & -0.167 & 1 & & & \\
\hline $\mathrm{Cl}^{-}$ & 0.646 & 0.681 & 0.752 & 0.799 & 0.802 & -0.106 & 1 & & \\
\hline $\mathrm{HCO}_{3}^{-}$ & 0.538 & 0.941 & 0.963 & 0.880 & 0.909 & -0.219 & 0.737 & 1 & \\
\hline $\mathrm{SO}_{4}^{-2}$ & 0.489 & 0.870 & 0.876 & 0.940 & 0.868 & -0.012 & 0.753 & 0.883 & 1 \\
\hline
\end{tabular}




\section{Suların kullanım özellikleri}

Çalışma alanında yüzey ve kaynak sularından alınan su örneklerinin $\mathrm{NO}_{3}$ ve ağır metal analiz sonuçları Çizelge 3'te verilmiştir. Yüzey ve kaynak sularına ait örneklerin analiz sonuçları; Sağlık Bakanlığı tarafından hazırlanmış İnsani Tüketim Amaçlı Sular Hakkında Yönetmelik'te (2005) ve Orman ve $\mathrm{Su}$ İşleri Bakanlığı tarafından hazırlanmış İçme Suyu Elde Edilen veya Elde Edilmesi Planlanan Yüzeysel Suların Kalitesine Dair Yönetmelik'te (2012) belirtilen limit değerler ile karşılaştırılmıştır. Yapılan değerlendirmeye göre yüzey ve kaynak sularına ait su örneklerinin tamamı ölçülen parametreler kapsamında içme suyu olarak kullanıma uygundur.
Çalışma alanındaki yüzey ve kaynak sularının sulamada kullanılabilirliğini belirlemek için Sodyum Adsorbsiyon Oranları (SAR) ve Özgül Elektriksel İletkenlik (EC) değerleri ABD Tuzluluk Laboratuvarı Diyagramı'nda kullanılmıştır.

Çalışma alanında bulunan sular 'C1S1' sınıfindadır (Şekil 6). Bu sınıflamaya göre sular; bitkiler için çoğu sulama suyu olarak kullanılabilen 'az tuzlu su' ve sodyuma karşı duyarlı olan bitkiler dışında her türlü tarım için uygun olan 'az sodyumlu su' özelliğindedir. $\mathrm{Bu}$ sonuç çalışma alanı ve yakın çevresindeki suların genel anlamda tüm sulama faaliyetlerinde kullanılabilecek özellikte sular olduğunu göstermektedir.

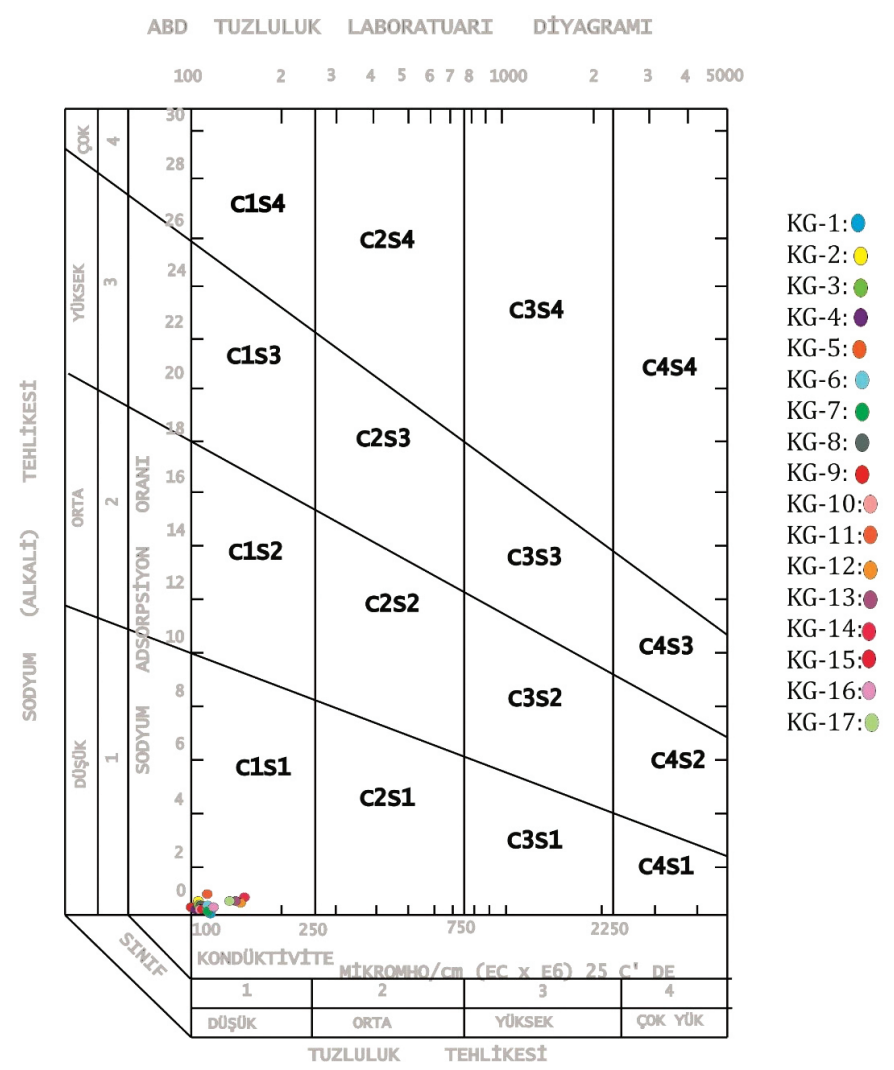

Şekil 6. Analiz edilen su örneklerin ABD Tuzluluk Laboratuvarı Diyagramı.

Figure 6. US Salinity Laboratory Diagram of the water samples analysed. 


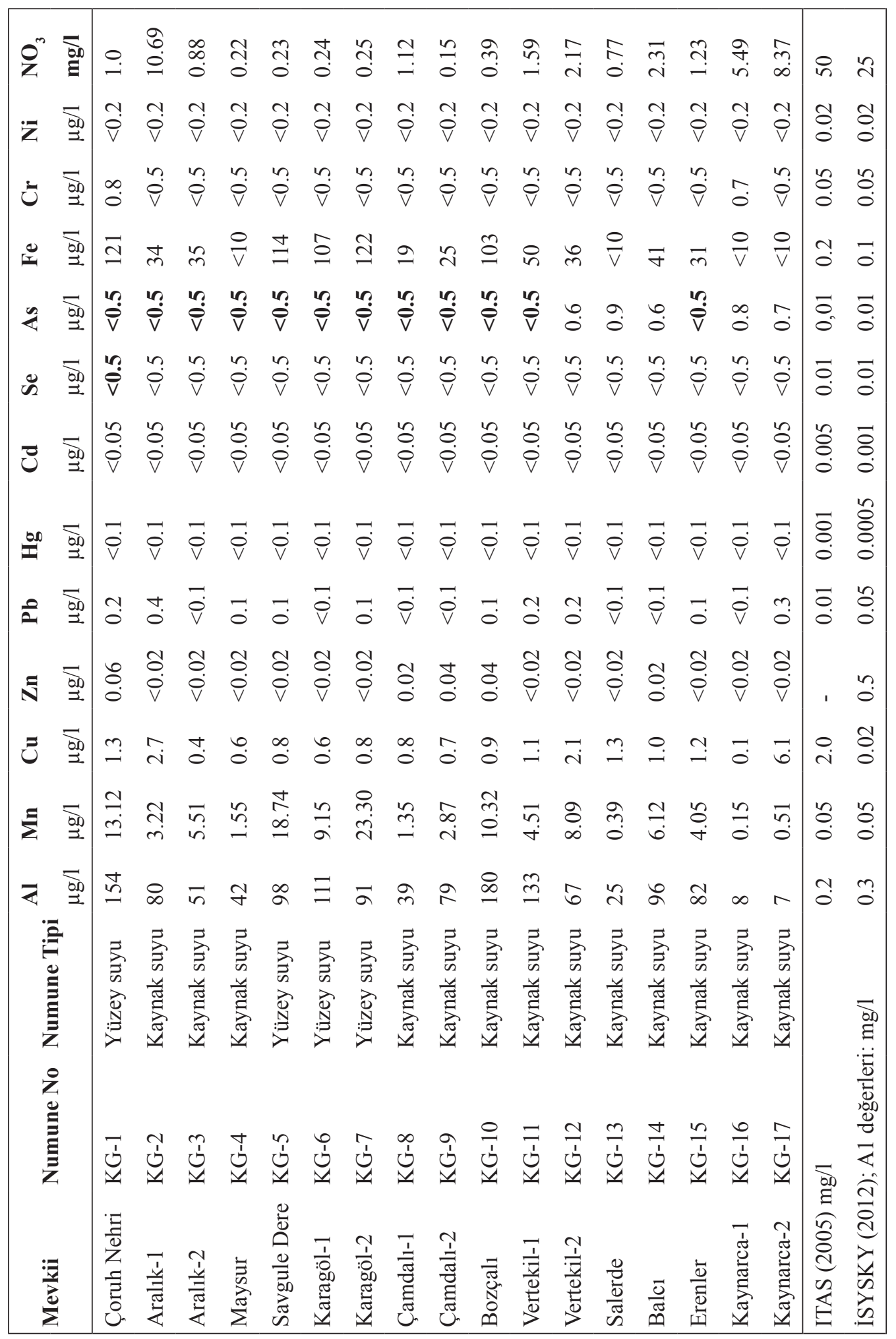


Çalışma alanındaki yüzey sularının kalite sinıflandırılmasında $\mathrm{Su}$ Kirliliği Kontrol Yönetmeliği'nde (2008) belirlenen Kita İçi $\mathrm{Su}$ Kaynaklarının Sinıflarına Göre Kalite Kriterleri'ne ait limit değerler kullanılmıştır. Yapılan değerlendirmeye göre çalışma alanındaki yüzey ve kaynak sularının tamamının genel olarak I. su kalite sınıfında olduğu görülmektedir.

\section{SONUÇLAR VE ÖNERILER}

Çalışma alanında yer alan Bakırköy formasyonu şeyl, marn ve killi kireçtaşı içeriği nedeniyle "Akifüj” olarak sınıflandırılmıştır. Kabaköy formasyonuna ait andezit, bazaltik lav, kireçtaşı, kumtaşı; Çayırbağı formasyonuna ait riyolitik, riyodasitik lav; Çağlayan formayonuna ait bazaltik lav, piroklast, çamurtaşı, kumtaş1 çökelleri; Kızılkaya formasyonuna ait dasit, riyodasit lav içerikleri ve kırık-çatlaklı yapıları nedeniyle "Yersel Verimli Çatlaklı Kaya Akiferi" olarak sınıflandırılmıştır. Alüvyon ve Yamaç Molozları ise bölgedeki yayılımları ve litolojik özellikleri dikkate alınarak "Az Verimli Gözenekli Akifer" olarak sınıflandırılmıştır. Su örneklerinin tamamının genel olarak $\mathrm{Ca}-\mathrm{HCO}_{3}$ ve $\mathrm{Ca}-\mathrm{Mg}-\mathrm{HCO}_{3}$ 'lü sular fasiyesinde olduğu görülmektedir. Çoruh Nehri'nden alınan KG-1 nolu su örneği ise $\mathrm{Na}-\mathrm{HCO}_{3}$ 'lü sular fasiyesinde yer almaktadır. Gibbs Diyagramı'nda ise, su örneklerinin tamamı "Kayaç Baskın" bölgesine düşmektedir.

İncelenen sularda $\mathrm{Ca}, \mathrm{Mg}$, $\mathrm{Na}$ ve $\mathrm{K}$ iyonları toplam katyona göre sirasiyla ortalama \% 65.6, $\% 18.2, \% 11.7$ ve $\% 4.5$ bir değere sahiptir. Anyonlardan ilk siray1 \%90.2 ile $\mathrm{HCO}_{3}^{-}, \% 6.1$ ile $\mathrm{SO}_{4}^{-2}$ ve $\% 3.7$ ile $\mathrm{Cl}^{-}$iyonları almaktadır. $\mathrm{Su}$ tiplerinin gelişmesindeki ana etken kayaçsu etkileşimi olup bölgede yüzeyleyen formasyonların litolojik ve mineralojik bileşimlerine bağlı olarak su örneklerinde Ca-
$\mathrm{Mg}-\mathrm{Na}$ ve $\mathrm{HCO}_{3}$ iyonları baskındır. Ortaç ve mafik magmatik kayaçlarda yoğun olarak $\mathrm{Na}-\mathrm{Ca}$ feldspat ve koyu renkli silikat mineralleri (biyotit, amfibol, piroksen) hakimdir. Genel olarak $\mathrm{Na}$ ve $\mathrm{Ca}$ iyonlarının artışı $\mathrm{Na}-\mathrm{Ca}$ feldspatlar ile, $\mathrm{Mg}$ iyonları ise daha çok biyotit, amfibol, piroksen gibi silikat minerallerinin ayrışması sonucunda gerçekleşmektedir. Su örneklerindeki baskın $\mathrm{HCO}_{3}$ iyonu ise bölgede yer yer çökelmiş olan kireçtaş1, killi kireçtaşı birimleri ile birlikte feldispat minerallerinin ayrışması sonucunda açığa çıkan kalsit mineraleri ile ilişkili kaya-su etkileşimi sonucunda artış göstermektedir. Major iyonlar arasında yapılan korelasyon analizlerine göre $\mathrm{Ca}$ iyonu $\mathrm{Na}$ ve $\mathrm{HCO}_{3}$ ile çok yüksek pozitif korelasyon, $\mathrm{Mg}, \mathrm{Cl}$ ve $\mathrm{SO}_{4}$ ile yüksek pozitif korelasyon sunmaktadır. $\mathrm{Mg}$ iyonu $\mathrm{SO}_{4}$ ile çok yüksek pozitif korelasyona, $\mathrm{Na}$ iyonu ise $\mathrm{HCO}_{3}$ ile çok yüksek pozitif korelasyona sahiptir. K iyonu ise diğer tüm iyonlar ile negatif korelasyon göstermektedir.

Yapılan değerlendirmeye göre yüzey ve kaynak sularından alınan su örneklerinin tamamı, analiz edilen parametreler kapsamında içme suyu olarak kullanıma uygundur. Çalışma alanı ve yakın çevresindeki suların genel anlamda tüm sulama faaliyetlerinde kullanılabilecek özellikte sular olduğunu göstermektedir. Çalışma alanı içerindeki su kaynaklarının Su Kirliliği Kontrol Yönetmeliğgi'ne göre değerlendirilmesi sonucunda, yüzey ve kaynak sularının tamamı tüm parametreler bakımından I. su kalite sinıfinda yer almaktadır.

\section{KATKI BELİRTME}

Bu çalışma Süleyman Demirel Üniversitesi Fen Bilimleri Enstitüsü Jeoloji Mühendisliği Anabilim Dalı'nda yapılan yüksek lisans tez çalışmasının bir ürünüdür. Yazarlar, çalışmayı finansal olarak destekleyen Süleyman Demirel 
Üniversitesi Bilimsel Araştırma Projeleri Yönetim Birimi Başkanlığı'na (Proje No: 4489YL1-15) teşekkür eder.

\section{KAYNAKLAR}

Güven, İ. H., Tosun, C. Y., 1986. Artvin-Borçka Karagöl Sahası Maden Jeolojisi Raporu. MTA Yayınları, Rapor No: 8021, Ankara.

Kopar, I., Sever, R., 2008. Karagöl (Borçka-Artvin). Atatürk Üniversitesi Sosyal Bilimler Enstitüsü Dergisi. 1, 21-38.

Şahinci, A., 1991. Doğal Suların Jeokimyası. Reform Matbaas1, 548 s, İzmir.
T.C. Resmi Gazete, 2005. İnsani Tüketim Amaçlı Sular Hakkında Yönetmelik, 25730.

T.C. Resmi Gazete, 2008. Su Kirliliği ve Kontrol Yönetmeliği, 25687.

T.C. Resmi Gazete, 2012. İçme Suyu Elde Edilen veya Elde Edilmesi Planlanan Yüzeysel Suların Kalitesine Dair Yönetmelik, 28338.

Yılmaz, B. S., Gülibrahimoğlu, İ., Konak, O., Yazıc1, E. N., Köse, Z., Yaprak, S., Çuvalcı, F., Saraloğlu, A., Tosun, C.Y., 1998. Artvin İlinin Çevre Jeolojisi ve Doğal Olanakları. MTA Yayınları, s: 1-223. Ankara. 
